\title{
Potential effects of essential oil from Zanthoxylum limonella seeds against Tribolium castaneum (Coleoptera: Tenebrionidae)
}

\author{
Ruchuon Wanna*, Bunyaporn Satongrod
}

\author{
Department of Agricultural Technology, Faculty of Technology, Mahasarakham University, Kantarawichai District, Maha \\ Sarakham 44150, Thailand
}

\section{*Corresponding author: ruchuon.w@msu.ac.th}

\begin{abstract}
Essential oils of plants with insecticidal properties have been considered as replacements for synthetic chemical pesticides to combat and control insect pests. The chemical composition of the essential oil from dried seeds of Zanthoxylum limonella Alston was determined by the Gas Chromatograph-Mass Spectrometry technique. Insecticidal activity was investigated on Tribolium castaneum Herbst using impregnated filter paper with six concentrations of essential oil at $0,1,2,3,4$, and 5\% for adults and larvae mortality tests, and $0,2,4,6,8$ and $10 \%$ for egg mortality. All experiments were performed under completely randomized design (CRD) with four replications at $30 \pm 5^{\circ} \mathrm{C}$ and $70 \pm 5 \%$ relative humidity in $16: 8$ hours light/dark cycle. A total of 83 components were identified. The principal compounds in the essential oil of Z. limonella were beta-pinene (19.65\%), 9-octadecanone (18.80\%), D-limonene (9.76\%), alpha-fenchene (8.48\%), p-mentha-1,5,8-triene (7.16\%), 1,8-cineole (6.88\%), gamma-terpinene (5.46\%), terpinen-4-ol (3.81\%), linalool $(2.73 \%)$, alpha-thujene (1.34\%), decanal (1.32\%), alpha-phellandrene (1.20\%) and linalyl propionate (1.13\%). Insecticidal activity presented that $5 \%$ of essential oil had the highest effect against $T$. castaneum at $120 \mathrm{~h}$ for adults and $48 \mathrm{~h}$ for larvae, while $10 \%$ of essential oil at 14 days obtained $100 \%$ mortality against eggs of $T$. castaneum. Results indicated that the essential oil of $Z$. limonella from dried seeds showed potential for use in the control of $T$. castaneum.
\end{abstract}

Keywords: chemical composition; essential oil; insecticidal activity; plant extract; Tribolium castaneum.

Abbreviations: Conc._concentration; CRD_completely randomized design; GC-MS_gas chromatograph-mass spectrometry; RT_retention time.

\section{Introduction}

Red flour beetle, Tribolium castaneum (Herbst) (Coleoptera: Tenebrionidae), is one of the most widespread and destructive primary insect pests of stored grain products in the tropics (Rees, 2004). Infestations of grain storage insects not only cause great losses through consumption of grains but also increase temperature and moisture, leading to accelerated growth of mold, including toxigenic species (Magan et al., 2003). Procedures used to control stored grain insect pests include physical, chemical and biological methods (Isman, 2006). Infestations of stored grain insect pests can be controlled by synthetic insecticides such as organophosphates, pyrethroids, and fumigants (mainly phosphine and methyl bromide) (Kljajic and Peric, 2006; Islam et al., 2010). However, repeated use and extreme reliance on fumigant insecticides intensify ozone depletion and environmental pollution. Costs of application and pesticide residues in food have increased, while insect pests have developed insecticidal resistance. Use of chemicals induces toxicity hazards to non-target organisms with direct toxicity to users (Isman, 2006; Ogendo et al., 2008; Rossi et al., 2010). These problems have highlighted the need to develop new selective insect control alternatives with fumigant actions. Interest in the use of plant extracts for the protection of agricultural products has resulted from their low mammalian toxicity and reduced persistence in the environment (Papachristos and Stamopoulos, 2002).

Research and development of environmentally safer, targetspecific and cost-effective insecticides against stored grain insect pests have recently increased. New approaches have concentrated on the use of natural products of plant origin, known as botanical derivatives. Botanical natural products are biodegradable, environmentally friendly and inexpensive, with no negative effects on non-target organisms and varied novel modes of action (George et al., 2014). Studies have focused on the use of active natural products from various plant essential oils and their bioactive chemical constituents as possible alternatives to synthetic insecticides (Rajendran and Sriranjini, 2008). Among these botanical natural products, various highly volatile essential oils are currently used in the food, perfume, cosmetic and pharmaceutical industries (Bayala et al., 2014). Essential oils can be synthesized and extracted from all plant 
organs as flowers, buds, seeds, leaves, twigs, bark, herbs, wood, fruits and root (Burt, 2004). They are mainly formed by mixtures of monoterpenes, sesquiterpenes, phenylpropanoids and metabolites that have organoleptic characteristics and biological activities (Stefanello et al., 2011). Essential oils are now considered to be important natural resources that can act as insecticides (Geetha and Roy, 2014), with low mammalian toxicity and rapid degradation in the environment (Bakkali et al., 2008). Essential oils derived from plants show varied bioactivities against stored grain insect pests ranging from toxicity with ovicidal (Mondal and Khalequzzaman, 2009; Ajayi and Olonisakin, 2011), larvicidal (Tapondjou et al., 2005), pupicidal (Pendey et al., 2018) and adulticidal activities (Wanna et al., 2018; Wanna and Krasaetep, 2019; Wanna and Kwang-Ngoen, 2019) that include oviposition deterrence and repellent actions (Elhag, 2000; Wanna and Khangkhun, 2018).

Plant families known as excellent sources of essential oils with insecticidal properties include the Rutaceae. This family comprises almost 150 genera and 1,600 species of trees, shrubs, and climbers distributed throughout the temperate and tropical regions of the world (Pollio et al., 2008). Members of the Rutaceae family have been used in perfumery, gastronomy and traditional medicine, while several publications have reported the presence of secondary chemical constituents of Rutaceae. A phytochemical survey of Rutaceae revealed a richness of alkaloids, coumarins, flavonoids, limonoids, and volatile oils (Lewis, 1983; Supabphol and Tangjitjareonkun, 2014), and the genus Zanthoxylum provided a variety of secondary metabolites including alkaloids, aromatic and aliphatic amides, lignans and coumarins with important phytochemical and biological activities (Adesina, 2005; Yang, 2008). The genus Zanthoxylum comprises over 200 species distributed worldwide, and especially in Eastern and Southeast Asia, America and Africa (Supabphol and Tangjitjareonkun, 2014). Various species of this genus are used for medicinal purposes such as stomachache, toothache, intestinal worms, rheumatism, scabies, snakebites, fever and cholera (Arun and Paridhavi, 2012).

Zanthoxylum limonella (Dennst.) Alston. (Rutaceae) occurs in the northern region of Thailand as an evergreen tree that grows up to $50 \mathrm{~m}$ high. The volatile oils of this aromatic plant contain a complex mixture of terpenic compounds (Ngassoum et al., 2003). These aromatic compounds are stored in the pericarp, while unsaturated fatty acids rich in oil accumulate in the seeds (Yamazaki et al., 2007). Different parts of $Z$. limonella have been used in Thai traditional medicine, while the fruits and the seeds are used as a spice (Ma-khwaen). Essential oil extracts from $Z$. limonella are reported to possess biological activities including reducing muscle strain (Oliver-Bever, 1982) and some metabolites have shown cytotoxic, antibacterial, anti-inflammatory, antifungal and anesthetic features with also antimalarial and anti-tuberculosis properties (Das et al., 2003; Charoenying et al., 2008; Nanasombat and Wimutigosol, 2011). Apart from historical use as a folk medicine, natural products of this plant have gained attention as biopesticides in crop production to reduce chemical pesticide applications (Copping, 1996; Harada, 1999). Here, chemical compositions of the essential oil from dried seeds of Zanthoxylum limonella Alston were evaluated for their insecticidal activity against egg larvae and adult stages of the stored grain insect pest $T$. castaneum Herbst.

\section{Results}

\section{Identification of compounds}

The main chemical composition percentages of essential oil from the dried seeds of $Z$. limonella by steam distillation are given in Table 1. GC-MS analysis identified and quantified 83 different components. These included beta-pinene (19.65\%), 9-octadecanone (18.80\%), D-limonene (9.76\%), alphafenchene (8.48\%), p-mentha-1,5,8-triene (7.16\%), 1,8-cineole $(6.88 \%)$ and gamma-terpinene $(5.46 \%)$ at more than $5 \%$ with terpinen-4-ol (3.81\%), linalool (2.73\%), alpha-thujene (1.34\%), decanal (1.32\%), alpha-phellandrene (1.20\%) and linalyl propionate $(1.13 \%)$ at over $1 \%$. A further 70 constituents were identified at less than $1 \%$.

\section{Mortality test}

All the essential oil solutions tested revealed significant toxicity against adults, larvae and eggs of $T$. castaneum. The mortality rate was concentration dependent and increase in concentration exacerbated mortality. Table 2 shows adult mortality of $T$. castaneum exposed to concentrations of up to $5 \%$ essential oil from Z. limonella. After treatment for $120 \mathrm{~h}$, $5 \%$ concentration resulted in mortality at $100 \%$, with the highest significant difference $(P<0.01)$. Larvae mortality of $T$. castaneum exhibited $100 \%$ mortality within $48 \mathrm{~h}$ at $5 \%$ essential oil concentration, with the highest significant difference $(P<0.01)$. Data of percentage larvae mortality with oil concentration are shown in Table 3. Z. limonella essential oil had greater efficiency against adults and larvae of $T$. castaneum when compared with $0 \%$ (acetone treatment), while $1 \%$ and $2 \%$ also gave high significant differences. Egg mortality of $T$. castaneum at 14 days after treatment was highest at a concentration of $10 \%$ Z. limonella essential oil, with a value of $100 \%$ and significant difference $(P<0.01)$ in relation to the other concentrations (Table 4). The oil concentration required to kill eggs was double the value for adult and larvae mortality. Results indicated that essential oil from Z. limonella demonstrated high mortality against $T$. castaneum, with increased performance at higher concentration levels. T. castaneum in larvae and adult stages were more sensitive to essential oil of $Z$. limonella at greater concentrations during the first $48 \mathrm{~h}$, and adapted as time passed. Essential oil from the dried seeds of $Z$. limonella showed high potential as an insecticide.

\section{Discussion}

Z. limonella oil consists of two main chemical compounds as limonene (43.63\%) (+)-sabinene (16.72\%) and terpinen-4-ol (10.95\%) (Charoensup et al., 2016). Limonene is a monoterpene that possesses the smell of oranges, and has been applied for food and cosmetic products (Itthipanichpong et al., 2002; Tangjitjaroenkun et al., 2012). Jirovetz et al. (1998) collected Z. limonella seeds from Kerala in Southern India and extracted them by the steam distillation method. They identified 41 different compounds in the essential oil, representing $98.3 \%$ of the oil composition. The seed oil was 
Table 1. Main chemical composition percentages of the essential oil from Z. limonella seeds.

\begin{tabular}{lll}
\hline Compound & Retention time $(\mathrm{min})$ & Area\% \\
\hline alpha-thujene & 3.83 & 1.34 \\
gamma-terpinene & 3.97 & 5.46 \\
camphene & 4.22 & 0.14 \\
beta-pinene & 4.67 & 19.65 \\
alpha-fenchene & 4.86 & 8.48 \\
alpha-phellandrene & 5.13 & 1.20 \\
alpha-terpinene & 5.35 & 0.21 \\
p-mentha-1,5,8-triene & 5.55 & 7.16 \\
D-limonene & 5.65 & 9.76 \\
1,8-cineole & 5.71 & 6.88 \\
linalool & 7.06 & 2.73 \\
eucalyptol & 7.74 & 0.06 \\
citronellal & 8.28 & 0.15 \\
terpinen-4-ol & 9.02 & 3.81 \\
linalyl propionate & 9.32 & 1.13 \\
decanal & 9.56 & 1.32 \\
beta-citronellol & 10.10 & 0.33 \\
9-octadecanone & 11.90 & 18.80 \\
\hline
\end{tabular}

Table 2. Adult mortality of T. castaneum treated with Z. limonella essential oil from $24 \mathrm{~h}$ to $168 \mathrm{~h}$.

\begin{tabular}{|c|c|c|c|c|c|c|c|}
\hline \multirow{2}{*}{$\begin{array}{l}\text { Conc. } \\
(\%)\end{array}$} & \multicolumn{7}{|c|}{ Mean ( \pm SE) of adult mortality (\%) of $T$. castaneum } \\
\hline & $24 \mathrm{~h}$ & $48 \mathrm{~h}$ & $72 \mathrm{~h}$ & $96 \mathrm{~h}$ & $120 \mathrm{~h}$ & $144 \mathrm{~h}$ & $168 \mathrm{~h}$ \\
\hline 0 & $0.00 \pm 0.00^{\mathrm{d}}$ & $0.00 \pm 0.00^{d}$ & $0.00 \pm 0.00^{\mathrm{d}}$ & $0.00 \pm 0.00^{d}$ & $0.00 \pm 0.00^{\mathrm{e}}$ & $0.00 \pm 0.00^{\mathrm{d}}$ & $0.00 \pm 0.00^{\mathrm{d}}$ \\
\hline 1 & $0.00 \pm 0.00^{d}$ & $0.00 \pm 0.00^{d}$ & $0.00 \pm 0.00^{d}$ & $0.00 \pm 0.00^{d}$ & $3.06 \pm 10.16^{\mathrm{e}}$ & $3.06 \pm 10.16^{d}$ & $3.06 \pm 10.16^{d}$ \\
\hline 2 & $0.00 \pm 0.00^{d}$ & $0.00 \pm 0.00^{d}$ & $5.00 \pm 5.77^{d}$ & $7.50 \pm 5.00^{d}$ & $7.50 \pm 9.57^{d}$ & $10.28 \pm 8.18^{d}$ & $10.28 \pm 8.18^{d}$ \\
\hline 3 & $15.00 \pm 5.77^{c}$ & $15.00 \pm 5.77^{c}$ & $20.00 \pm 0.00^{c}$ & $25.00 \pm 5.77^{c}$ & $28.89 \pm 4.71^{\mathrm{c}}$ & $39.44 \pm 9.36^{\mathrm{C}}$ & $42.22 \pm 8.56^{\mathrm{c}}$ \\
\hline 4 & $35.00 \pm 5.77^{b}$ & $35.00 \pm 5.77^{b}$ & $42.50 \pm 9.57^{b}$ & $50.00 \pm 8.16^{b}$ & $55.28 \pm 4.10^{b}$ & $60.56 \pm 9.36^{b}$ & $76.11 \pm 10.36^{b}$ \\
\hline 5 & $70.00 \pm 8.16^{\mathrm{a}}$ & $87.50 \pm 5.00^{a}$ & $95.00 \pm 5.77^{a}$ & $97.50 \pm 5.00^{\mathrm{a}}$ & $100.00 \pm 0.00^{a}$ & $100.00 \pm 0.00^{a}$ & $100.00 \pm 0.00^{a}$ \\
\hline
\end{tabular}

Table 3. Larvae mortality of $T$. castaneum treated with Z. limonella essential oil after $24 \mathrm{~h}$ to $72 \mathrm{~h}$.

\begin{tabular}{lccc}
\hline \multirow{2}{*}{ Conc. (\%) } & \multicolumn{3}{l}{ Mean $( \pm \mathrm{SE})$ of larvae mortality (\%) of T. castaneum } \\
\cline { 2 - 4 } & $24 \mathrm{~h}$ & $48 \mathrm{~h}$ & $72 \mathrm{~h}$ \\
\hline 0 & $0.00 \pm 0.00^{\mathrm{d}}$ & $0.00 \pm 0.00^{\mathrm{e}}$ & $0.00 \pm 0.00^{\mathrm{e}}$ \\
1 & $0.00 \pm 0.00^{\mathrm{d}}$ & $20.00 \pm 0.00^{\mathrm{d}}$ & $32.50 \pm 5.00^{\mathrm{d}}$ \\
2 & $0.00 \pm 0.00^{\mathrm{d}}$ & $42.50 \pm 5.00^{\mathrm{c}}$ & $70.00 \pm 8.16^{\mathrm{c}}$ \\
3 & $25.00 \pm 5.77^{\mathrm{c}}$ & $75.00 \pm 5.77^{\mathrm{b}}$ & $87.50 \pm 5.00^{\mathrm{b}}$ \\
4 & $45.00 \pm 5.77^{\mathrm{b}}$ & $97.50 \pm 5.00^{\mathrm{a}}$ & $100.00 \pm 0.00^{\mathrm{a}}$ \\
5 & $65.00 \pm 5.77^{\mathrm{a}}$ & $100.00 \pm 0.00^{\mathrm{a}}$ & $100.00 \pm 0.00^{\mathrm{a}}$ \\
\hline \multicolumn{4}{l}{}
\end{tabular}

Table 4. Egg mortality of T. castaneum treated with Z. limonella essential oil for 14 days.

\begin{tabular}{lc}
\hline Conc. (\%) & Mean $( \pm$ SE) of egg mortality (\%) of T. castaneum \\
\hline 0 & $0.00 \pm 0.00^{\mathrm{e}}$ \\
2 & $25.00 \pm 5.77^{\mathrm{d}}$ \\
4 & $55.00 \pm 5.77^{\mathrm{c}}$ \\
6 & $82.50 \pm 5.00^{\mathrm{b}}$ \\
8 & $97.50 \pm 5.00^{\mathrm{a}}$ \\
10 & $100.00 \pm 0.00^{\mathrm{a}}$ \\
\hline & Means within the same column followed by the same letter are not significantly different (DMRT: $P>0.05)$.
\end{tabular}

rich in sabinene $(47.12 \%)$, alpha-terpineol $(7.73 \%)$, terpinen-4ol $(6.61 \%)$, beta-pinene $(5.99 \%)$, limonene $(4.06 \%)$, alphapinene $(3.87 \%)$, gamma-terpinene $(3.64 \%)$, alpha-terpinene (3.45\%) and para-cymene (3.08\%). The secondary metabolites present in this plant constitute a protection system against stored grain insect pest attacks. Itthipanichpong et al. (2002) investigated chemical compounds contained in the essential oil distilled from the fruit of $Z$. limonella in Thailand. They found 33 different components with limonene (31.1\%), terpinene-4ol $(13.9 \%)$ and sabinene $(9.1 \%)$ as the major monoterpenes. Thus, variation in environmental, ecological and geographical conditions as well as culture and extraction techniques affects 
volatile oil chemical components. Such conditions alter the biosynthetic pathway of the plant resulting in diverse essential oils (Supabphol and Tangjitjareonkun, 2014).

Findings suggested that the concentrations of $Z$. limonella essential oil affect the degree of toxicity, time to mortality, and mortality rates. Aromatic plant compounds are stored in the pericarp, while oil and unsaturated fatty acids accumulate in the seed (Yamazaki et al., 2007). Tripathi et al. (2003) showed that the application of limonene suppressed oviposition and threatened adult survival of stored product pests.

Limonene was also determined as the major component of the essential oil of Anethum sowa that deterred oviposition in Callosobruchus maculatus females (Tripathi et al., 2000). Limonene, as the most abundant component in Z. limonella oil, belongs to a class of natural compounds known as limonoid terpenes (Bruno, 2004). Limonoids are secondary metabolites produced in plants in the family Rutaceae, and display a wide range of biological activities including insecticidal, insect antifeedant and growth regulation (Bayazit and Konar, 2010). Furthermore, limonoids impact the oviposition of insects due to nutritional disruption which ultimately induces antifeedant effects (Murray et al., 1995).

\section{Materials and Methods}

\section{Insect rearing}

Adults of the red flour beetle $T$. castaneum Herbst were obtained from infested stored seeds collected from Maha Sarakham Province, Thailand. A colony of $T$. castaneum was started with 30 adults. The colony was reared and maintained on wheat flour mixed with wheat and yeast $(13: 1 \mathrm{w} / \mathrm{w})$ in plastic bottles (diameter $23 \mathrm{~cm}$, height $30 \mathrm{~cm}$ ) covered with a fine mesh cloth for ventilation at $30 \pm 5^{\circ} \mathrm{C}, 70 \pm 5 \%$ relative humidity, and 16:8 h light/dark cycle for development of progenies. Adults that emerged after 7 days were used to evaluate the mortality efficiency of essential oil, while the third instar larvae aged 1 day and eggs aged 3 days were used for the larvicidal and ovicidal tests. All experiments were conducted under the same environmental conditions.

\section{Extraction of essential oil}

Essential oil was extracted from the seeds of $Z$. limonella Alston obtained from Maha Sarakham in the northeast of Thailand. Extraction of essential oil was performed from dried seeds (200 g of sample with $600 \mathrm{ml}$ of distilled water) using a Clevenger-type apparatus and steam distilled for $3 \mathrm{~h}$ at the Department of Agricultural Technology, Faculty of Technology, Mahasarakham University. Essential oil of Z. limonella was centrifuged to separate the water and kept in a vial with the lid tightly closed in a refrigerator at $4^{\circ} \mathrm{C}$ until required for use.

\section{Analysis of essential oil}

The essential oil volatile constituents were established by gas chromatography-mass spectrometry (GC-MS) analyses performed on a Clarus SQ $8 \mathrm{GC} / \mathrm{MS}$ system (PerkinElmer, MA, USA) operating in El mode (70 eV). A Rtx-5MS capillary column (with a 5\% phenyl-methylpoly siloxane stationary phase, $30 \mathrm{~m}$ $x 0.25 \mathrm{~mm}, 0.25 \mu \mathrm{m}$ film thickness) was used. GC settings were as follows: initial oven temperature was kept at $50^{\circ} \mathrm{C}$ for $1 \mathrm{~min}$ and then increased to $180^{\circ} \mathrm{C}$ at a rate of $10^{\circ} \mathrm{C} / \mathrm{min}$, held for 1 min, and then increased at $3^{\circ} \mathrm{C} / \mathrm{min}$ to $240^{\circ} \mathrm{C}$ for $15 \mathrm{~min}$. Injector temperature was maintained at $230^{\circ} \mathrm{C}$. Samples $(1 \mu \mathrm{l}$, diluted to $1 \%$ with acetone) were injected with a split ratio of $1: 10$. The carrier gas was helium with a flow rate of 1.0 $\mathrm{ml} / \mathrm{min}$. Spectra were scanned from 45 to $450 \mathrm{~m} / \mathrm{z}$. Identification of essential oil components was undertaken by comparing their mass spectra with those stored in the National Institute of Standards and Technology (NIST) Mass Spectral Search Program and the ChemStation Wiley Spectral Library. Essential oil components were identified by comparison of their retention times with authentic samples to a series of $n$ alkanes under the same operating conditions.

\section{Mortality test}

Mortality testing was conducted on adults, larvae and eggs. A series of dilutions of essential oil from $Z$. limonella $(0,4,8,12$, 16 and $20 \%$ ) was prepared using $100 \%$ acetone as solvent as described. An aliquot of each dilution $(1 \mathrm{ml})$ was separately applied on the top surface of a filter paper (diameter $9 \mathrm{~cm}$ ). The solvent was allowed to evaporate for $5 \mathrm{~min}$ before placing the filter paper into a Petri dish (diameter $9 \mathrm{~cm}$ ). Ten female adults of $T$. castaneum (7 days) were introduced separately into each Petri dish. The number of dead and live insects in each Petri dish was observed after incubation at $30 \pm 5^{\circ} \mathrm{C}, 70 \pm$ $5 \%$ relative humidity, $16: 8 \mathrm{~h}$ light/dark cycle and $24 \mathrm{~h}$ to $168 \mathrm{~h}$ exposure. Insects were considered to be dead if no sign of leg or antennal movements were detected. A control experiment was performed whereby treatment involved $100 \%$ acetone alone. Each set of treatments was repeated four times.

Six concentrations of $0,1,2,3,4$ and $5 \%$ of essential oil from $Z$. limonella were prepared for the larvicidal test with acetone as solvent. An aliquot of each dilution $(1 \mathrm{ml})$ was separately applied on the top surface of a filter paper (diameter $9 \mathrm{~cm}$ ). The filter paper was then left to dry at room temperature for 5 min. Control samples were treated only with pure acetone and dried in the same way. Ten third instar larvae of $T$. castaneum (1 day) were randomly selected, placed into each Petri dish and kept at $30 \pm 5^{\circ} \mathrm{C}, 70 \pm 5 \%$ relative humidity, $16: 8 \mathrm{~h}$ light/dark cycle. The experiment was replicated four times and larvae mortalities were recorded after $24 \mathrm{~h}$ to $72 \mathrm{~h}$ of treatment.

Ten eggs ( 3 days) of $T$. castaneum were placed into a Petri dish containing $0.5 \mathrm{~g}$ of wheat flour. An aliquot of $0.5 \mathrm{ml}$ essential oil of $Z$. limonella was then added and the Petri dish (diameter $9 \mathrm{~cm}$ ) was sealed and kept at $30 \pm 5^{\circ} \mathrm{C}, 70 \pm 5 \%$ relative humidity, 16:8 h light/dark cycle. A control sample was treated with only $1 \mathrm{ml}$ acetone. After 14 days, the mortality of eggs was counted under a stereo microscope. Sterile eggs that failed to hatch were then counted. Each set of treatments was repeated four times.

All mortality percentages were determined as described in our previous experiment and calculated using the Abbott's formula (Abbott, 1925).

\section{Statistical analysis}

The treatments were operated using a completely randomized design (CRD) with four replications. Statistical analysis was performed using one-way analysis of variance (ANOVA). Data 
were presented as means \pm SE. Significantly differences at $P$ value $\leq 0.05$ among means were determined by the DRMT test.

\section{Conclusions}

The essential oil from dried seeds of $Z$. limonella contained 84 components. The main compounds were beta-pinene (19.65\%) and 9-octadecanone (18.80\%). Z. limonella essential oil displayed insecticidal activity against adults, larvae and eggs of T. castaneum with potential of $100 \%$ adult mortality. Essential oil from dried seeds of $Z$. limonella is an interesting alternative to conventional chemical control strategies. Effectiveness of essential oil compounds might be a viable option to control stored grain insect pests. Natural products are an optimal alternative to chemical control for stored grain insect pest control. Z. limonella essential oil offers a safe and eco-friendly alternative to synthetic pesticides. Results for developing new natural insecticides to protect stored products as plant essential oil are encouraging, as an alternative to synthetic chemicals. However, further studies are required to evaluate the safety of these oils before large-scale use for stored grain product insect control.

\section{Acknowledgments}

This research was financially supported by the Faculty of Technology, Mahasarakham University (Grant year 2019). Laboratory assistance from Miss Jiraporn Krasaetep and Miss Tonyong Sadomphruk is gratefully acknowledged.

\section{References}

Abbott WS (1925) A method for computing the effectiveness of an insecticide. J Econ Entomol. 18: 265-267.

Adesina S (2005) The Nigerian Zanthoxylum; chemical and biological values. Afr J Tradit Complem. 2(3): 282-301.

Ajayi FA, Olonisakin A (2011) Bio-activity of three essential oils extracted from edible seeds on the rust-red flour beetle, Tribolium castaneum (Herbst.) infesting stored pearl millet. Trakia J Sci. 9(1): 28-36.

Arun KKV, Paridhavi M (2012) An ethno botanical phytochemical and pharmacological utilization of widely distributed species Zanthoxylum: a comprehensive overview. Int J Pharm. 2: 24-35.

Bakkali F, Averbeck S, Averbeck D, Idaomar M (2008) Biological effects of essential oils: a review. Food Chem Toxicol. 46(2): 446-75.

Bayala B, Bassole IH, Scifo R, Gnoula C, Morel L, Lobaccaro JMA, Simpore J (2014). Anticancer activity of essential oils and their chemical components: a review. Am J Cancer Res. 4(6): 591-607.

Bayazit V, Konar V (2010) Biochemical and physiological evaluations of limnoids as potential cancer destroyers. J Anim Vet Adv. 9(7): 1099-1107.

Bruno G (2004) Building immunity and promoting wellness with botanicals and antioxidants. Literature education series on dietary supplements [Online]. Available from: http://www.hchs.edu/literature/Immunity\%20Wellness.pdf [Accessed on $18^{\text {th }}$ February, 2020]

Burt S (2004) Essential oils: Their antibacterial properties and potential applications in foods: a review. Int J Food Microbiol. 94(3): 223-53.
Charoensup R, Duangyod T, Phuneerub P, Singharachai C (2016) Pharmacognostic specifcation of Zanthoxylum limonella (Dennst.) Alston: fruits and seeds in Thailand. J Adv Pharm Technol Res. 7: 134-138.

Charoenying P, Laosinwattana C, Phuwiwat W, Lomratsiri J (2008) Biological activities of Zanthoxylum limonella Alston fruit extracts. KMITL Sci J. 8: 12-15.

Copping LG (1996) Crop protection agents from nature: natural products and analogues. The Royal Society of Chemistry, Cambridge, United Kingdom

Das NG, Baruah I, Talukdar PK, Das SC (2003) Evaluation of botanicals as repellents against mosquitoes. J ArthropodBorne Di. 40: 49-53.

Elhag EA (2000) Deterrent effects of some botanical products on oviposition of the cowpea bruchid Callosobruchus maculatus (F.) (Coleoptera: Bruchidae). Int J Pest Manage. 46(2): 109-113.

Geetha R, Roy A (2014) Essential oil repellents: a short review. Int J Drug Dev Res. 6(2): 20-27.

George DR, Finn RD, Graham KM, Sparagano OA (2014) Present and future potential of plant-derived products to control arthropods of veterinary and medical significance. Parasit Vectors. 7(1): 1-12.

Harada J (1999) Weed Science in Year 2000s in Asia-Pacific Region. In Proceedings I (A) of the 17th Asian-Pacific weed science society conference: weeds and environmental impact, Bangkok, Thailand, pp 9-12

Islam MS, Hasan MM, Lei C, Mucha-Pelzer T, Mewis I, Ulrichs C (2010) Direct and admixture toxicity of diatomaceous earth and monoterpenoids against the storage pests Callosobruchus maculatus (F.) and Sitophilus oryzae (L.). J Pest Sci. 83: 105-112.

Isman MB (2006) Botanical insecticides, deterrents and repellents in modern agriculture and an increasingly regulated world. Annu Rev Entomol. 51: 45-66.

Itthipanichpong C, Ruangrungsi N, Pattanaautsahakit C (2002) Chemical compositions and pharmacological effects of essential oil from the fruit of Zanthoxylum limonella. J Med Assoc Thai. 85(Suppl 1): 344-354.

Jirovetz L, Buchbauer G, Shafi MP, Saidutty A (1998) Analysis of the aroma compounds of the essential oil of seeds of the spice plant Zanthoxylum rhetsa from southern India. Z Lebensm Unters Forsch. 206(3): 228-229.

Kljajic P, Peric I (2006) Susceptibility to contact insecticides of granary weevil Sitophilus granarius (L.) (Coleoptera: Curculionidae) originating from different locations in the former Yugoslavia. J Stored Prod Res. 42: 149-161.

Lewis JR (1983) Biological activity of some Rutaceous compounds. In: Waterman PG, Grundon MF, (eds) Chemistry and chemical taxonomy of Rutales, Academic Press, London, United Kingdom

Magan N, Hope R, Cairns V, Aldred D (2003) Postharvest fungal ecology: impact of fungal growth and mycotoxin accumulation in stored grain. Eur J Plant Pathol. 109: 723730.

Mondal M, Khalequzzaman M (2009) Ovicidal activity of essential oils against red flour beetle, Tribolium castaneum (Herbst) (Coleoptera: Tenebrionidae). J Biol Sci. 17: 57-62.

Murray KD, Groden E, Drummond FA, Alford AR, Conley S, Storch RH, Bentley MD (1995) Citrus limonoid effects on Colorado potato beetle (Coleoptera: Chrysomelidae) 
colonization and oviposition. Environ Entomol. 24(5): 12751283.

Nanasombat S, Wimutigosol P (2011) Antimicrobial and antioxidant activity of spice essential oils. Food Sci Biotechnol. 20: 45-53.

Ngassoum MB, Essia-Ngang JJ, Tatsadjieu LN, Jirovetz L, Buchbauer G, Adjoudji O (2003) Antimicrobial study of essential oils of Ocimum gratissimum leaves and Zanthoxylum xanthoxyloides fruits from Cameroon. Fitoterapia. 74: 284-287.

Ogendo O, Kostyukovsky M, Ravid U, Matasyoh J, Deng A, Omolo E (2008) Bioactivity of Ocimum gratissimum L. and two of its constituents against five insect pests attacking stored food products. J Stored Prod Res. 44: 328-334.

Oliver-Bever B (1982) Medicinal plants in tropical West Africa. I. Plants acting on the cardiovascular system. J Ethnopharmacol. 5: 1-72.

Papachristos DP, Stamopoulos DC (2002) Repellent, toxic and reproduction inhibitory effects of essential oil vapours on Acanthoscelides obtectus (Say) (Coleoptera: Bruchidae). J Stored Prod Res. 38: 117-128.

Pendey AK, Tripathi S, Singh P (2018) Plant essential oils: a substitute for conventional insecticides against Tribolium species (Coleoptera: Tenebrionidae)-achievements and challenges. Arch Phytopathol Pflanzenschutz. 51(13-14): 696728.

Pollio A, De Natale A, Appetiti E, Aliotta G, Touwaide A (2008) Continuity and change in the Mediterranean medical tradition: Ruta spp. (Rutaceae) in hippocratic medicine and present practices. J Ethnopharmacol. 116: 469-482.

Rajendran S, Sriranjini V (2008) Plant products as fumigants for stored-product insect control. J Stored Prod Res. 44: 126135.

Rees D (2004) Insects of stored products. CSIRO Publishing, Collingwood, Vic., Australia, p 181

Rossi E, Cosimi S, Loni A (2010) Insecticide resistance in Italian populations of Tribolium flour beetles. Bull Insectology. 63(2): 251-258.

Stefanello MEA, Pascoal AC, Salvador MJ (2011) Essential oils from neotropical Myrtaceae: chemical diversity and biological properties. Chem Biodivers. 8(1): 73-94.
Supabphol R, Tangjitjareonkun J (2014) Chemical constituents and biological activities of Zanthoxylum limonella (Rutaceae): a review. Trop J Pharm Res. 13(12): 2119-2130.

Tangjitjaroenkun J, Chavasirib W, Thunyaharnc S, Yompakdee C (2012) Bactericidal effects and time-kill studies of the essential oil from the fruits of Zanthoxylum limonella on multi-drug resistant bacteria. J Essent Oil Res. 24: 363-370.

Tapondjou AL, Adlerb C, Fontemc DA, Boudaa H, Reichmuth C (2005) Bioactivities of cymol and essential oils of Cupressus sempervirens and Eucalyptus saligna against Sitophilus zeamais Motschulsky and Tribolium confusum du Val. J Stored Prod Res. 41: 91-102.

Tripathi A, Prajapati V, Aggarwal K, Khanuja S, Kumar S (2000) Repellency and toxicity of oil from Artemisia annua to certain stored-product beetles. J Econ Entomol. 93(1): 43-47.

Tripathi AK, Prajapati V, Khanuja SPS, Kumar S (2003) Effect of D-limonene on three stored-product beetles. J Econ Entomol. 96(3): 990-995.

Wanna R, Khangkhun P (2018) Toxicity and bioefficacy of weed essential oils against cowpea bruchids and their effect on mungbean seeds. Int J GEOMATE. 14(42): 14-19.

Wanna R, Krasaetep J (2019) Chemical composition and insecticidal activity of essential oil from Indian borage against maize weevil. Int J GEOMATE. 16(56): 59-64.

Wanna R, Kwang-Ngoen P (2019) Efficiency of Indian borage essential oil against cowpea bruchids. Int J GEOMATE. 16(56): 129-134.

Wanna R, Khangkhun P, Wongsawas M, Bunphan D (2018) Chemical compositions and efficacy of betel piper essential oil against red flour beetle, Tribolium castaneum (Herbst). Commun Agric Appl Biol Sci. 83(3): 256-263.

Yamazaki E, Inagaki M, Kurita O, Inoue T (2007) Antioxidant activity of Japanese pepper (Zanthoxylum piperitum DC.) fruit. Food Chem. 100: 171-177.

Yang X (2008) Aroma constituents and alkylamides of red and green Huajiao (Zanthoxylum bungeanum and Zanthoxylum schinifolium). J Agr Food Chem. 56(5): 1689-96. 